\title{
Microwave Enhanced Akabori Reaction for Peptide Analysis
}

\author{
Ajay K. Bose, Yao Hain Ing, Nina Lavlinskaia, and Chaitanya Sareen \\ Department of Chemistry and Chemical Biology, George Barasch Bioorganic Research Laboratory, \\ Stevens Institute of Technology, Hoboken, New Jersey, USA
}

\author{
Birendra N. Pramanik, Peter L. Bartner, Yan-Hui Liu, \\ and Larry Heimark \\ Schering-Plough Research Institute, Kenilworth, New Jersey, USA
}

\begin{abstract}
The Akabori reaction, devised in 1952 for the identification of C-terminus amino acids, involves the heating of a linear peptide in the presence of anhydrous hydrazine in a sealed tube for several hours. We report here a modified Akabori reaction that rapidly identifies the C-terminus amino acid in a polypeptide including its amino acid sequence information at both the C-terminus and the $\mathrm{N}$-terminus. This modified methodology demonstrates the fundamentals of microwave chemistry applied to bioanalytical problems. In this modified process, hydrazinolysis has been accelerated by the application of microwave irradiation. In our reaction, the linear peptide and hydrazine solution, contained in a loosely covered conical flask, was exposed to a few minutes of irradiation using an unmodified domestic microwave oven. While the classical Akabori reaction required several hours, the microwave assisted reaction takes just minutes. If dimethyl sulfoxide is added to dilute the reaction mixture, the process is retarded enough to allow aliquots of the reaction mixture to be drawn every few minutes over a period of about an hour in order to study the progress of hydrazinolysis. Reaction products were monitored by mass spectrometry-primarily FAB-MS. In addition to providing sequence information, the microwave enhanced Akabori reaction quickly detects the presence of arginine (Arg) by converting each Arg to ornithine (Orn). Furthermore, certain amino acids, containing $\beta-\mathrm{SH}, \mathrm{CO}_{2} \mathrm{H}$, and $\mathrm{CONH}_{2}$ groups in their side chain, are susceptible to modification by hydrazine, thereby, providing rapid confirmation of the presence of these amino acid residues. In these preliminary studies, the following oligopeptides were analyzed to demonstrate the effectiveness of our approach; the dipeptide (Trp-Phe), the tripeptide (Tyr-Gly-Gly), the tetrapeptide (Pro-Phe-Gly-Lys), the heptapeptide (Ala-Pro-Arg-Leu-ArgPhe-Tyr), and a N-terminal blocked tripeptide (N-acetyl-Met-Leu-Phe). (J Am Soc Mass Spectrom 2002, 13, 839-850) (c) 2002 American Society for Mass Spectrometry
\end{abstract}

$\mathrm{T}$ The growth of biotechnology has led to a dramatic increase in the need for the rapid identification of peptide sequences [1-3]. There are satisfactory, if time consuming, methods in wide use today based on stepwise Edman degradation [4] that provide the sequence from the $\mathrm{N}$-terminus of a peptide. However, an adequate general method for the determination of the C-terminus is not available [5].

The Akabori reaction [6], devised half a century ago, involved heating linear peptides with anhydrous hydrazine under reflux at $125^{\circ} \mathrm{C}$ for several hours. The C-terminus group is liberated as a free amino

Published online June 11, 2002

Address reprint requests to Dr. B. N. Pramanik, Schering-Plough Research Institute, 2015 Galloping Hill Road, Kenilworth, NJ 07033-0539. E-mail: birendra.pramanik@spcorp.com acid and can be easily distinguished from the remaining amino acid residues that have been converted to hydrazides. Scheme 1 illustrates this mechanism.

In the course of our studies on microwave assisted chemistry, the application of microwave irradiation to the Akabori reaction was investigated [7]. Preliminary findings from the limited data were very promising. It was observed that microwave irradiation reduced the time required for the completion of the Akabori reaction from hours to minutes. Also, this approach provided information not only about the C-terminus but also the $\mathrm{N}$-terminus. In addition, this method provided quantitative data on the presence of certain amino acid residues with functional groups that are altered by reaction with hydrazine (Arg, Asn, Asp, Cys, Glu, Gln, etc.). In light of these findings we felt encouraged to undertake an extensive investigation of microwave enhanced Akabori reaction. 

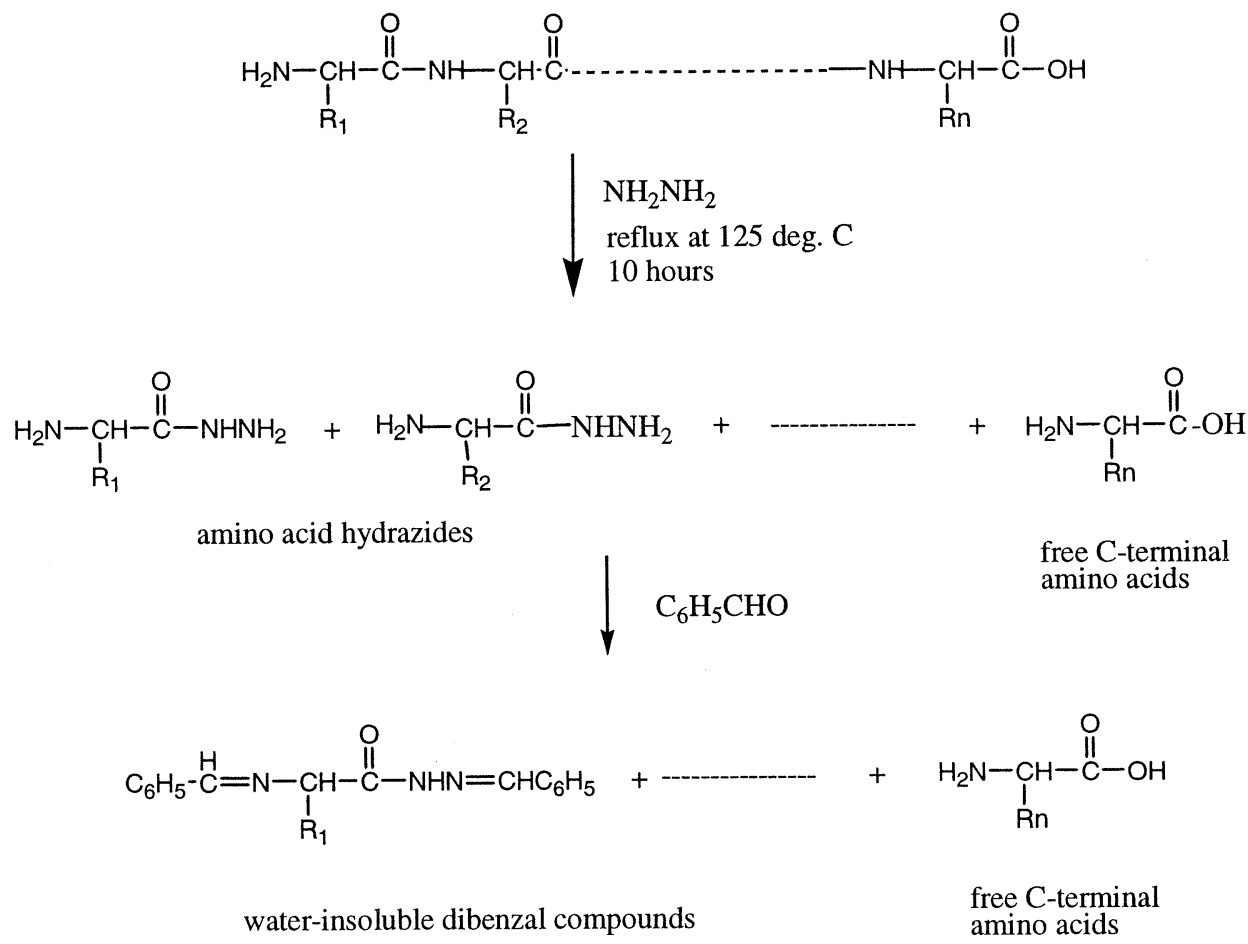

Scheme 1 Akabori hydrazinolysis of oligopeptides.

\section{Microwave Technology}

Microwave assisted organic chemistry is a new field. Two seminal papers [8,9] appeared in 1986 that demonstrated that a variety of organic reactions could be completed in minutes instead of hours when conducted in sealed glass or Teflon vessels in domestic microwave ovens. A few explosions caused by the rapid rise of pressure in sealed systems were also reported. One approach to avoid such explosions was developed by Bose et al. [10-12] under the name of Microwaveinduced Organic Reaction Enhancement (MORE) chemistry. This approach involves reactions in open vessels with limited amounts of a higher boiling polar solvent such as acetonitrile, $N, N$-dimethylformamide (DMF), chlorobenzene. The microwave energy input is controlled so that the bulk temperature of the reaction mixture is at least $20^{\circ} \mathrm{C}$ below the boiling point of the reaction medium. Therefore, there is very limited vaporization and no reflux condensers are needed.

A different approach $[13,14]$ for removing the risk of explosion is the use of solventless ("dry") reactions involving reagents adsorbed on clays, alumina, silica gel or other suitable solid support. It is interesting to note that commercially available Montmorrilonite clay is essentially transparent to microwaves but reagents absorbed on clay are able to absorb microwave energy and undergo rapid reaction.

Microwaves are a non-ionizing radiation that transfers energy to ions in solution and to compounds with dipole moment. Glass, hydrocarbons, and symmetrical molecules (i.e., no diploes) absorb very little microwave energy. Solvents (such as water, DMF, DMSO) and compounds with dipole moment (e.g., esters, amides, alcohols, etc.) absorb microwave energy directly with efficiency.

Microwave irradiation cannot be considered as just a clean way of heating a reaction mixture. The large amount of data reported from various laboratories indicate that in most cases the reaction rate is increased substantially-although the mechanism is not well understood. Nonetheless, the ability of microwaves for improving several chemical processes or in modifying chemo-, regio-, or stereo-selectivity is being exploited

\section{Experimental Setup}
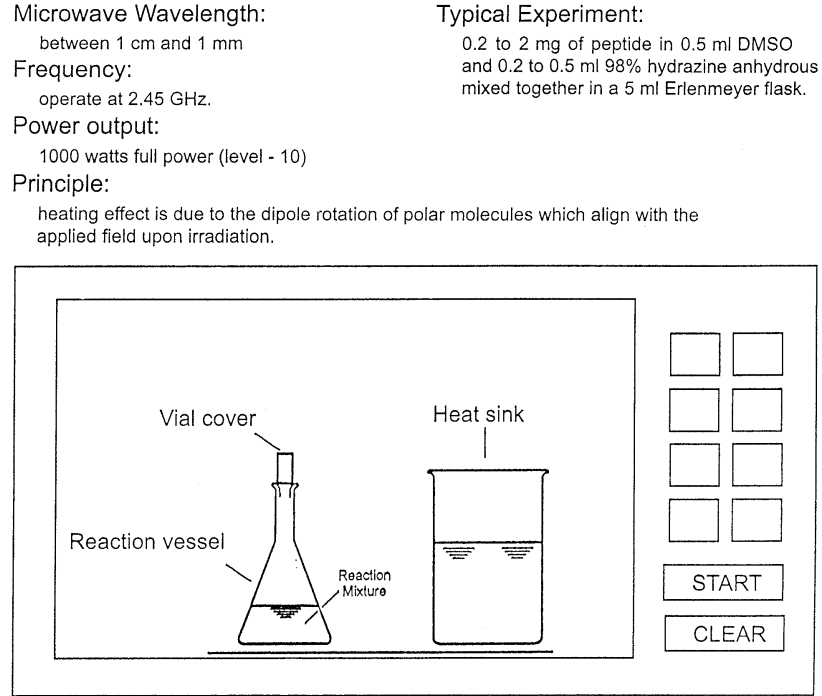

Figure 1. Experimental setup. 

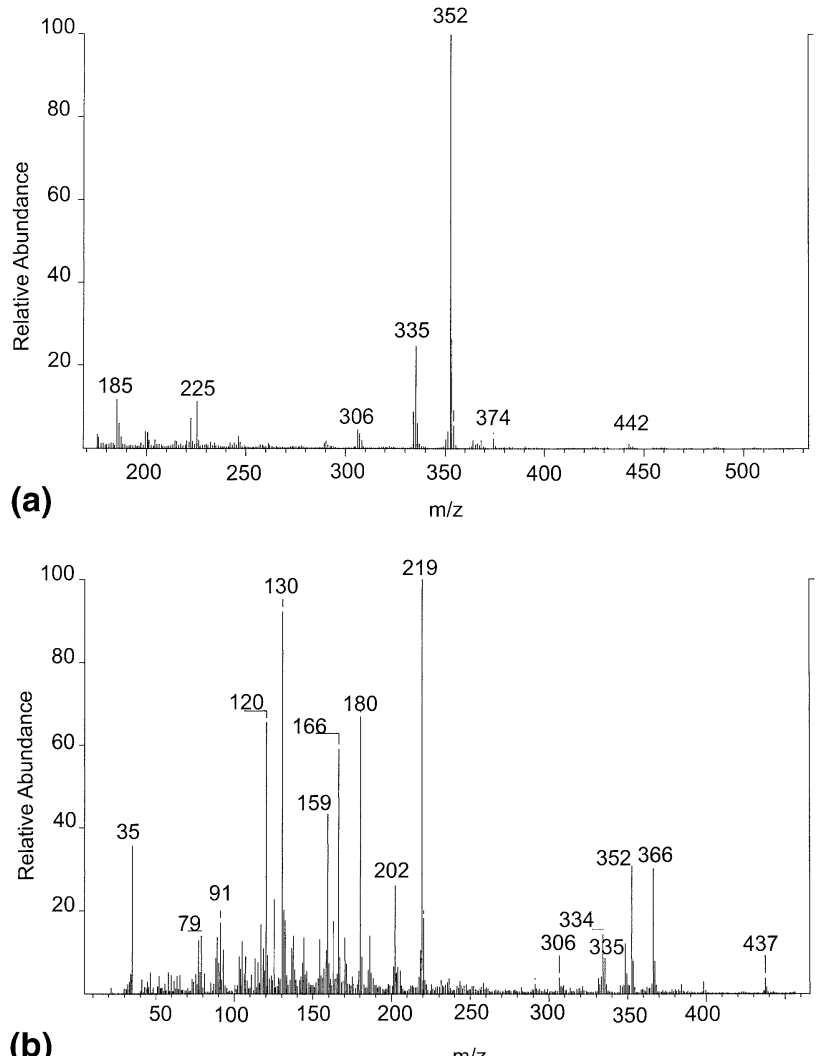

(b)

$\mathrm{m} / \mathrm{z}$

Figure 2. (a) FAB-MS of dipeptide H-Trp-Phe-OH/ $t=0$ min. (b) FAB-MS after partial hydrazinolysis of dipeptide H-Trp-Phe$\mathrm{OH} / t=30 \mathrm{~min}$.

by synthetic chemists. A comprehensive review was published in 1995 [15]. A few more recent publications and reviews [16-19] are cited to show the breadth of the microwave assisted organic synthesis field that covers heterocycles, natural products, peptides, catalytic reactions and many types of compounds of interest to medicinal chemists.

There appears to be only limited applications of microwave technology to the chemistry of peptides and proteins. Wang, Chen, and coworkers [20] described the use microwave irradiation for the hydrolysis in a few minutes of peptides and proteins sealed in a tube with $6 \mathrm{M} \mathrm{HCl}$. They also showed that various dipeptides containing aspartic acid were hydrolyzed much faster than other dipeptides without aspartic acid. This research group also developed procedures for increasing the coupling efficiency in solid phase peptide synthesis that required microwave irradiation for just a few minutes [21].

Bose et al. [11] have simplified the hydrolysis of oligopeptides by working with open systems (beakers or conical flasks) in domestic microwave ovens using sodium dihydrogen phosphate solution for acid hydrolysis. Basic hydrolysis of small peptides was conducted with a solution of barium hydroxide or a dilute solution of disodium hydrogen phosphate.

\section{Microwave Assisted Hydrazinolysis}

Initial experiments with $98 \%$ hydrazine and dipeptides and tripeptides showed that the Akabori reaction could be completed in 3-5 min under microwave irradiation. Then it was found that the reaction mixture of an oligopeptide and $98 \%$ hydrazine could be diluted with dimethyl sulfoxide (DMSO) [7] to slow down the hydrazinolysis. This allowed one to collect small samples at regular intervals for monitoring the rate of formation of various reaction products. Fast atom bombardment (FAB) mass spectrometry was used to analyze these samples directly - without the need for any work up.

The following oligopeptides were studied to illustrate the effectiveness of our approach; the dipeptide (Trp-Phe), the tripeptide (Tyr-Gly-Gly), the tetrapeptide (Pro-Phe-Gly-Lys), the heptapeptide (Ala-Pro-Arg-LeuArg-Phe-Tyr), and an N-terminal blocked tripeptide (N-acetyl-Met-Leu-Phe).

\section{Experimental Procedure}

Reactions were conducted inside an unmodified domestic microwave oven, the $1 \mathrm{cu} \mathrm{ft}$ General Electric, model JE1040. This unit provides up to 1000 watts adjustable in ten increments. A $5 \mathrm{ml}$ Erlenmeyer flask with a loose cover was used as the reaction vessel. The oligopeptide $(0.2$ to $2 \mathrm{mg}$ ) was dissolved in $0.5 \mathrm{ml}$ of DMSO with $0.2-0.5 \mathrm{ml}$ of $98 \%$ hydrazine. Because of the small size of the reaction mixture, a "heat sink" (see Figure 1) in the form of a beaker with about $350 \mathrm{ml}$ of cold water was placed next to the Erlenmeyer flask to reduce the amount of microwave energy available to<smiles>NCC(=O)NC(Cc1ccccc1)C(=O)O</smiles>

$\mathrm{m} / \mathrm{z}: 352$

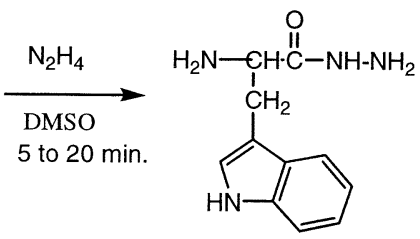

$[\mathrm{M}+\mathrm{H}]^{+}: \mathrm{C}_{11} \mathrm{H}_{15} \mathrm{O}_{1} \mathrm{~N}_{4}$ observed m/z: 219.1242 calculated m/z: 219.1246 error $[\mathrm{ppm}]:-1.7$

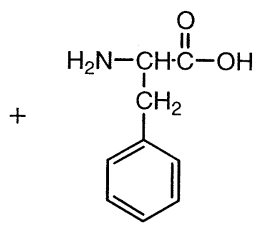

$[\mathrm{M}+\mathrm{H}]^{+}: \mathrm{C}_{9} \mathrm{H}_{12} \mathrm{O}_{2} \mathrm{~N}$

observed $\mathrm{m} / \mathrm{z}: 166.0865$

calculated $\mathrm{m} / \mathrm{z}: 166.0868$

error $[\mathrm{ppm}]: \quad-2.0$

Scheme 2 The Akabori reaction of Trp-Phe. 
<smiles>NC(Cc1c[nH]c2ccccc12)C(=O)NC(Cc1ccccc1)C(=O)O</smiles>

$\mathrm{m} / \mathrm{z}: 352$

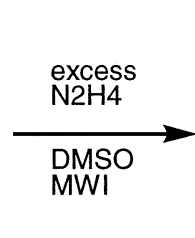

$[\mathrm{M}+\mathrm{H}]^{+}: \mathrm{C}_{20} \mathrm{H}_{24} \mathrm{O}_{2} \mathrm{~N}_{5}$ observed $\mathrm{m} / \mathrm{z}$ : 366.1920 calculated m/z: 366.1930 error $[\mathrm{ppm}]: \quad-2.7$

Scheme 3

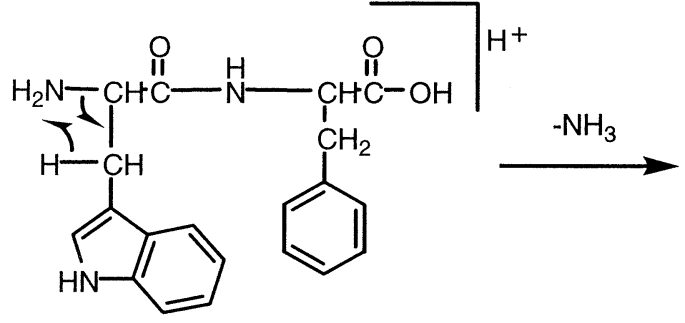

$\mathrm{m} / \mathrm{z}: 352$<smiles>CC[CH+]CC(=O)NC(Cc1ccccc1)C(=O)O</smiles>

$[\mathrm{M}+\mathrm{H}]^{+}: \mathrm{C}_{20} \mathrm{H}_{19} \mathrm{O}_{3} \mathrm{~N}_{2}$ observed m/z: $\mathbf{3 3 5 . 1 4 0 6}$ calculated $\mathrm{m} / \mathrm{z}: 335.1396$ error [ppm]: + 3.1

Scheme 4

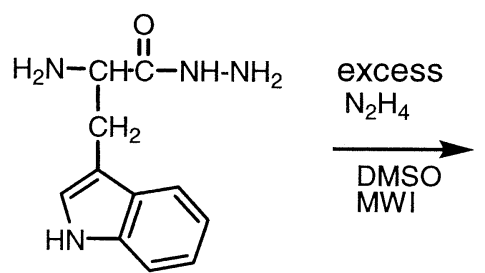

$\mathrm{m} / \mathrm{z}: 219$<smiles>C=C1C=Nc2ccccc21</smiles>

$[\mathrm{M}+\mathrm{H}]^{+}: \mathrm{C}_{9} \mathrm{H}_{8} \mathrm{~N}$ observed m/z: 130.0657 calculated m/z: 130.0657 error $[\mathrm{ppm}]: \quad+0.5$

Scheme 5<smiles>N[C](Cc1ccccc1)C(=O)O</smiles>

$[\mathrm{M}+\mathrm{H}]^{+}: \mathrm{C}_{9} \mathrm{H}_{12} \mathrm{O}_{2} \mathrm{~N}_{1}$ observed $\mathrm{m} / \mathrm{z}$ : 166.0865 calculated m/z: 166.0868 error $[\mathrm{ppm}]: \quad-2.0$

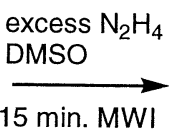<smiles>NNC(=O)Cc1ccccc1</smiles>

$[\mathrm{M}+\mathrm{H}]^{+}: \mathrm{C}_{9} \mathrm{H}_{14} \mathrm{O}_{1} \mathrm{~N}_{3}$ observed $\mathrm{m} / \mathrm{z}$ : 180.1137 calculated $\mathrm{m} / \mathrm{z}: 180.1137$ error $[\mathrm{ppm}]: \quad+0.3$ 
the reaction mixture and to protect the magnetron (microwave generator) from unabsorbed microwave energy reflected back to it. Hydrazinolysis was conducted in the microwave oven for a specified period of time ( 2 or $5 \mathrm{~min}$ ), the oven door was then opened and a small aliquot of the reaction mixture was withdrawn with a pipette for immediate analysis by FAB-MS using a matrix mixture of glycerol/thioglycerol (G/TG) or a mixture of nitrobenzyl alcohol and glycerol/thioglycerol (NBA-G/TG). Portion of the aliquot was also analyzed by LC ESI-MS The remaining sample was then reintroduced in the oven to continue the reaction.

\section{Results and Discussion}

\section{The Akabori Reaction of a Dipeptide}

The products formed in the Akabori reaction of the dipeptide, Trp-Phe, were as expected, the tryptophanyl hydrazide and the free phenylalanine amino acid.

Figure 2a provides the FAB-MS (3NBA-G-TG/ DMSO) of the starting material, Trp-Phe, while Figure $2 \mathrm{~b}$ provides the FAB-MS of the reaction products. The abundant ion at $m / z 166$ (Figure $2 \mathrm{~b}$ ) is consistent with a free amino acid formed from the carboxyl terminal phenylalanine and the abundant ion at $\mathrm{m} / \mathrm{z} 219$ is consistent with the expected tryptophanyl hydrazide. These structural assignments were supported by HRFAB-MS data as indicated in Scheme 2. Since this reaction was carried out with an excess of hydrazine, the starting dipeptide was partially converted to a hydrazide (Scheme 3 ) to give the ion at $m / z 366$ in Figure 2b.

The FAB fragment ion at $m / z 335$ (Figure $2 b$ ) corresponded to the neutral loss of $\mathrm{NH}_{3}$ from the parent ion, m/z 352 (Scheme 4).

Increasing the irradiation time from 5 to $10 \mathrm{~min}$ resulted in an increase in the formation of free amino acid (Phe) at $m / z 166$ and the tryptophanyl hydrazide at $\mathrm{m} / \mathrm{z} 219$. After $50 \mathrm{~min}$ of irradiation (not shown), almost all the starting material had been consumed and an ion at $m / z 130$ reached its greatest abundance. It is thought that this ion was produced by the degradation of the tryptophanyl hydrazide $(m / z 219)$ to form quinoline as shown in Scheme 5.

Note that this suggested structure was supported by HR-FAB-MS data. The abundance of the ion at $m / z 219$ increased steadily over time as the starting material, $\mathrm{m} / \mathrm{z}$ 352 , decreased. The abundance of the ion at $m / z 166$ peaked at about $30 \mathrm{~min}$ and then declined. This observation coincides with the increasing abundance of an ion at $m / z 180$ that is consistent with the conversion of the free amino acid to a hydrazide as shown in Scheme 6.

\section{The Akabori Reaction of a Tripeptide}

Figure 3 is the FAB-MS of the reaction products formed in the Akabori reaction of the tripeptide, H-Tyr-Gly-
Gly-OH. The expected Akabori ions were obtained in 1-5 min as indicated by the formation of a protonated dipeptide hydrazide H-Tyr-Gly- $\mathrm{NHNH}_{2}(\mathrm{~m} / z$ 253) and protonated glycine $(\mathrm{m} / \mathrm{z} 76)$. Continuation of this irradiation with excess hydrazine resulted in the disappearance of the starting tripeptide ion at $m / z 296$ accompanied by cleavage of $\mathrm{H}$-Tyr-Gly- $\mathrm{NHNH}_{2}$ to form H-Tyr$\mathrm{NHNH}_{2}\left(m / z\right.$ 196) and $\mathrm{H}-\mathrm{Gly}-\mathrm{NHNH}_{2}(\mathrm{~m} / \mathrm{z}$ 90) ions. Note that H-Gly-NHNH${ }_{2}$ can be also formed by hydrazinolysis of free glycine. These ions were confirmed by HR-FAB-MS data. The ion at $\mathrm{m} / \mathrm{z} 221$ corresponded to the loss of hydrazine from the dipeptide hydrazide at $m / z 253$, and is discussed in the next section. The ions $m / z$ 93, 107, 136, 154, and 185 are ascribed to background species from the matrix/solvent mixture. A summary of the mechanisms is provided in Scheme 7.

\section{Simplified Akabori Reaction of a Tetrapeptide}

Recently we have found that $98 \%$ hydrazine used in our previous studies can be conveniently replaced by aqueous hydrazine solutions of various strengths. The near optimum condition appears to be the use of hydrazine solution of $50-75 \%$ concentration. The bulk reaction temperature reaches $105-110{ }^{\circ} \mathrm{C}$ in just a few minutes and significant data can be obtained in about $30 \mathrm{~min}$.

This simpler procedure-without the need for expensive and somewhat unsafe pure hydrazine-was employed for the analysis of the tetrapeptide Pro-PheGly-Lys. In experiments using 50\% aqueous hydrazine as the reagent, the sample collected after $10 \mathrm{~min}$ of microwave irradiation indicated the presence of the expected tripeptide H-Pro-Phe-Gly- $\mathrm{NHH}_{2}$ at $\mathrm{m} / \mathrm{z} 334$ and the dipeptide H-Pro-Phe-NHNH 2 at $\mathrm{m} / \mathrm{z} 277$ formed by Akabori cleavage. After 15 min of irradiation a new ion appeared at $m / z 245$ which corresponds to the loss of $\mathrm{NH}_{2} \mathrm{NH}_{2}$ (32 Da) from H-Pro-Phe-NHNH . To determine whether this ion was a mass spectral fragment ion or the molecular ion of a diketopiperazine derived from Pro-Phe, we recorded the FAB-MS again with $\mathrm{LiBr}$ added. The $\mathrm{Li}^{+}$adduct ion appeared at the $m / z$ 251. Similarly, the ion at $m / z 277$ assigned to

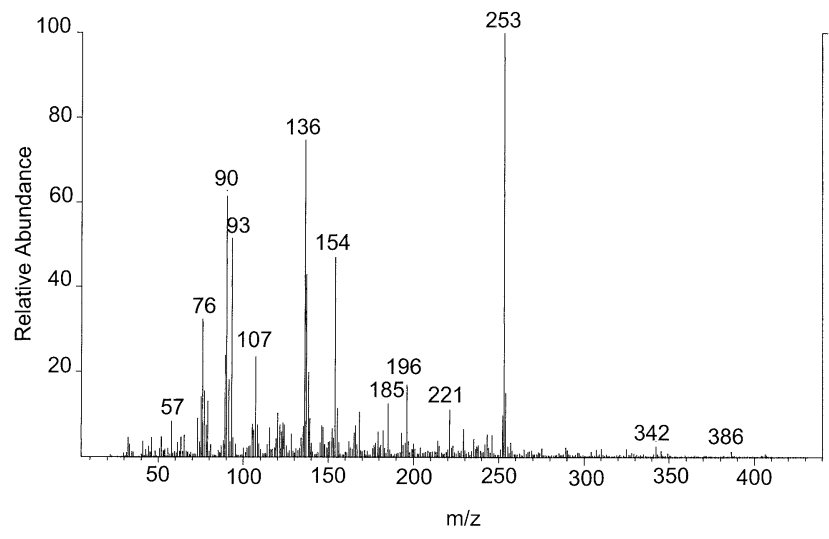

Figure 3. FAB-MS after partial hydrazinolysis of H-Tyr-Gly-Gly$\mathrm{OH} / t=20 \mathrm{~min}$ 

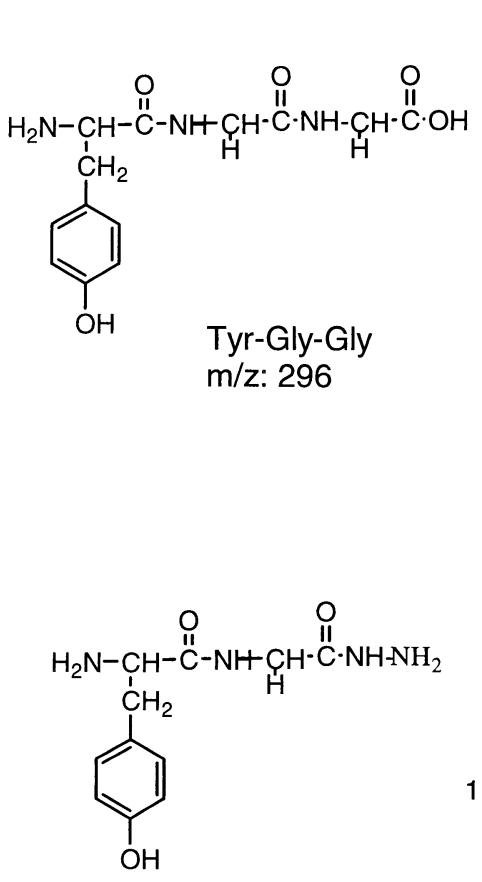

$\mathrm{m} / \mathrm{z}: 253$

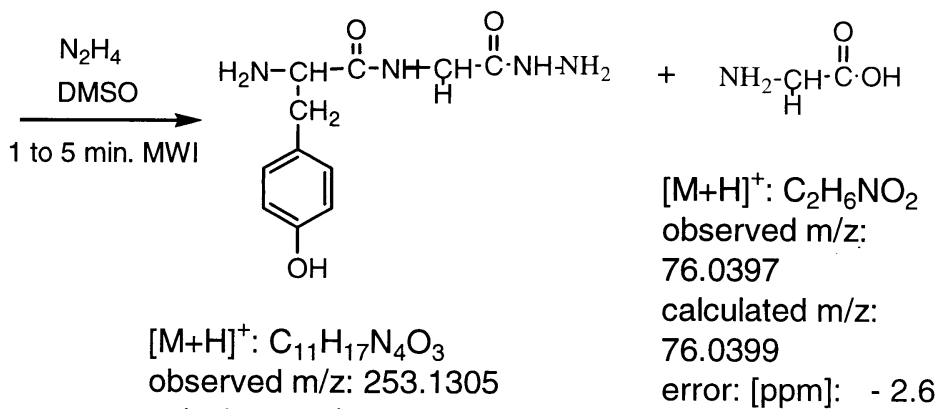

calculated m/z: 253.1301

error $[\mathrm{ppm}]:+1.6$

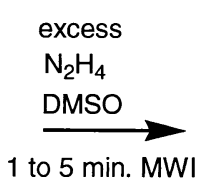

$[\mathrm{M}+\mathrm{H}]^{+}: \mathrm{C}_{9} \mathrm{H}_{14} \mathrm{~N}_{3} \mathrm{O}_{2}$ observed $\mathrm{m} / \mathrm{z}$ : 196.1083 calculated m/z: 196.1081 error $[\mathrm{ppm}]: \quad+1.0$

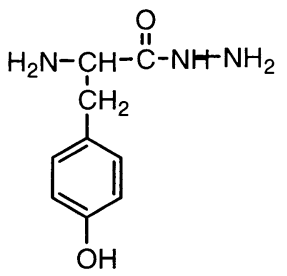

Scheme 7
Pro-Phe- $\mathrm{NHNH}_{2}$ provided a new ion at $m / z$ 283. By analogy, the ion at $m / z 221$ in the Akabori reaction on the tripeptide Tyr-Gly-Gly (Scheme 7) can be designated as the diketopiperazine from Tyr-Gly. Spectral data are shown in Figure $5 a$ and $b$.

\section{The Akabori Reaction of a Heptapeptide}

A more convincing evaluation of the microwave enhanced Akabori process is the hydrazinolysis of the heptapeptide, H-Ala-Pro-Arg-Leu-Arg-Phe-Tyr-OH. Figures $4 a, b, c, d$, and e provide the FAB-MS data obtained by monitoring this reaction over a period of 50 min at sampling times 2, 8, 10, 30, 50 min. Spectral data at additional sampling times were recorded but not included in Figure 4.

Prior to the addition of hydrazine to the heptapeptide solution $(t=0 \mathrm{~min})$, the protonated molecule at $\mathrm{m} / \mathrm{z}$ 922 was the base peak. Within a minute of the start of the Akabori reaction, the loss of $42 \mathrm{Da}$ from the molecular ion was observed. At 2 min (Figure 4a), the ion at $\mathrm{m} / \mathrm{z} 880$ had become moderately abundant although $\mathrm{m} / \mathrm{z}$ 922 ion remained as the base peak. At $8 \mathrm{~min}$ (Figure $4 \mathrm{~b}$ ), the most abundant ion was $m / z 880$ and an ion corresponding to the loss of a second $42 \mathrm{Da}$ appeared at $\mathrm{m} / \mathrm{z}$ 838. Akabori reaction products were first observed at the 10 min mark. At $20 \mathrm{~min}$ (Figure 4c), the ion at $\mathrm{m} / \mathrm{z}$ 838 became the base peak. Elemental compositions, obtained for the ions at $m / z 880$ and 838 , suggested that the double loss of $42 \mathrm{Da}\left(\mathrm{CH}_{2} \mathrm{~N}_{2}\right)$ was due to the conversion of arginine (Arg) to ornithine (Orn). This loss of exactly two units of $42 \mathrm{Da}$ is consistent with the presence of two Arg residues in this heptapeptide. The peptide, containing two Orn groups (20 min), will be referred to as the modified peptide. The low abundant ion at $m / z 852(838+14 \mathrm{Da})$, appearing at the 15 min mark, arose from the conversion of the $\mathrm{C}$-terminus acid group of the modified peptide $(\mathrm{m} / \mathrm{z} 838)$, to a hydrazide $\left(-\mathrm{CO}_{2} \mathrm{H} \rightarrow-\mathrm{CONHNH}_{2}\right)$. At $30 \mathrm{~min}$ (Figure $4 \mathrm{~d}$ ), the conventional Akabori cleavage ions had become prominent. Figure $4 \mathrm{e}$ (the reaction products after $50 \mathrm{~min}$ ) shows that very little of the modified heptapeptide, $\mathrm{m} / \mathrm{z}$ 838, remained while products consistent with conventional Akabori cleavage dominated. The ESI-MS insert in Figure $4 \mathrm{e}$ was obtained with the $50 \mathrm{~min}$ aliquot to bring out ions not observed in the FAB-MS. The suppression of certain peptide ions in the spectra of peptide mixtures is a common problem in FAB-MS. The ESI spectrum showed abundant ions at $m / z 443$ and 329, while these ions were detected in much lower abundance in the FAB mass spectrum (Figure 4e).

The Akabori reaction (Scheme 8) for the above heptapeptide was derived by careful examination of the FAB-MS data found in Figure 4.

The initial Akabori cleavage, involving the loss of C-terminus Tyr (tyrosine) from the modified heptapeptide $(m / z 838)$, resulted in the formation of the hexapeptide hydrazide at $m / z$ 689. Accurate mass measurement 

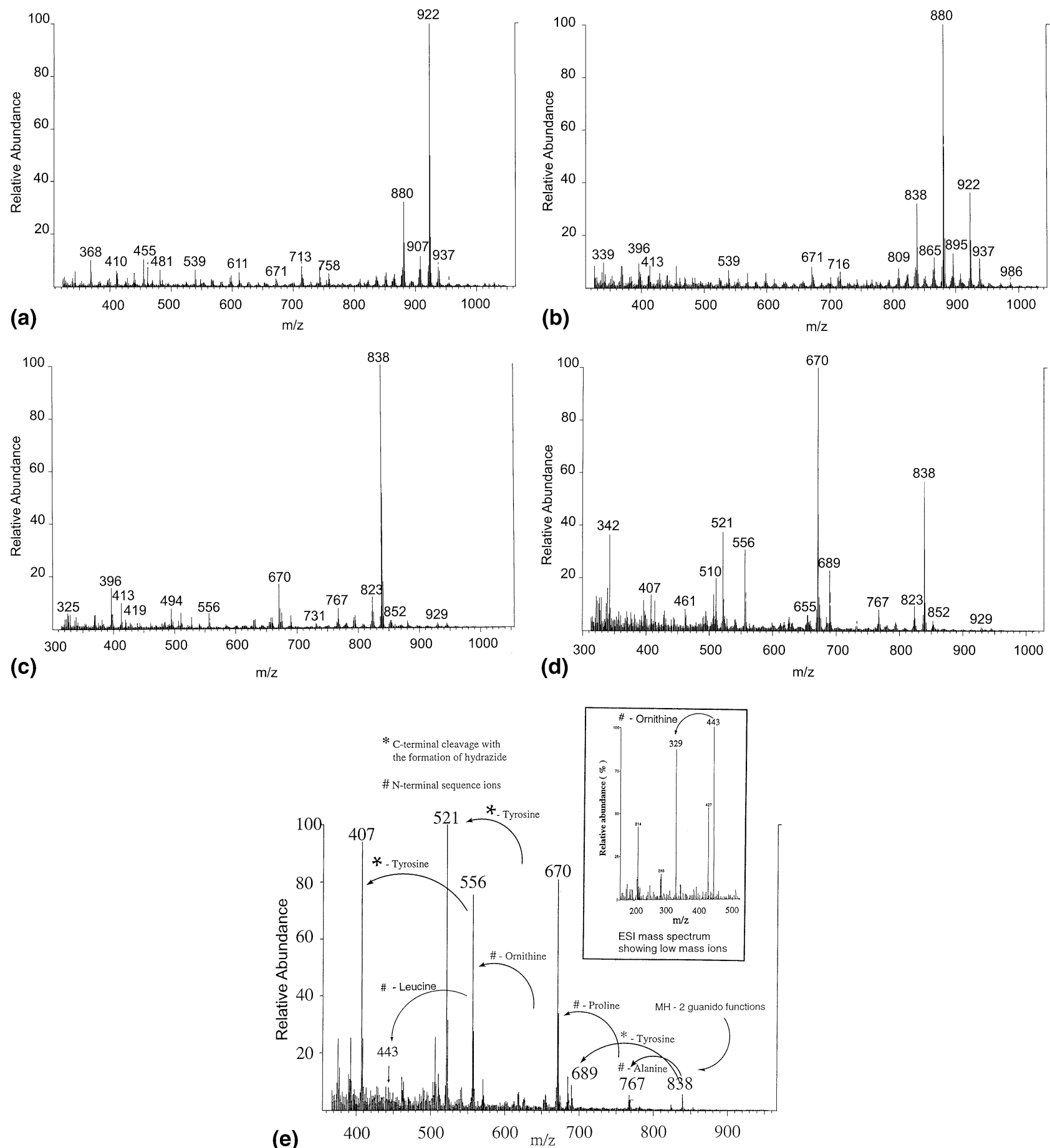

Figure 4. (a) FAB-MS of the hydrazinolysis of H-Ala-Pro-Arg-Leu-Arg-Phe-Tyr-OH $/ t=2 \mathrm{~min}$. (b) FAB-MS of the hydrazinolysis of H-Ala-Pro-Arg-Leu-Arg-Phe-Tyr-OH/t $=8 \mathrm{~min}$. (c) FAB-MS of the hydrazinolysis of H-Ala-Pro-Arg-Leu-Arg-Phe-Tyr-OH/t $=20 \mathrm{~min}$. (d) FAB-MS of the hydrazinolysis of H-Ala-Pro-Arg-Leu-Arg-Phe-Tyr-OH/t $=30 \mathrm{~min}$. (e) FAB-MS of the hydrazinolysis of H-Ala-ProArg-Leu-Arg-Phe-Tyr-OH $/ t=50 \mathrm{~min}$.

of this ion provided the expected elemental composition for the protonated ion, $[\mathrm{M}+\mathrm{H}]^{+}, \mathrm{C}_{33} \mathrm{H}_{57} \mathrm{~N}_{10} \mathrm{O}_{6}$. Two additional ions were produced by first order Akabori cleavage $\left(\mathrm{Aka}^{1}\right)$, the tetrapeptide at $\mathrm{m} / \mathrm{z} 521$ and the tripeptide at $\mathrm{m} / \mathrm{z} 407$. Both ions were observed in the 30 min spectrum (Figure $4 \mathrm{~d}$ ). In all three cases, the same C-terminal amino acid (H-Tyr-OH) was removed, but the peptide fragments were of different lengths because they had previously lost part of their $\mathrm{N}$-terminus sequence.

In addition to C-terminus Akabori cleavage, microwave assisted hydrazinolysis produced sequential 

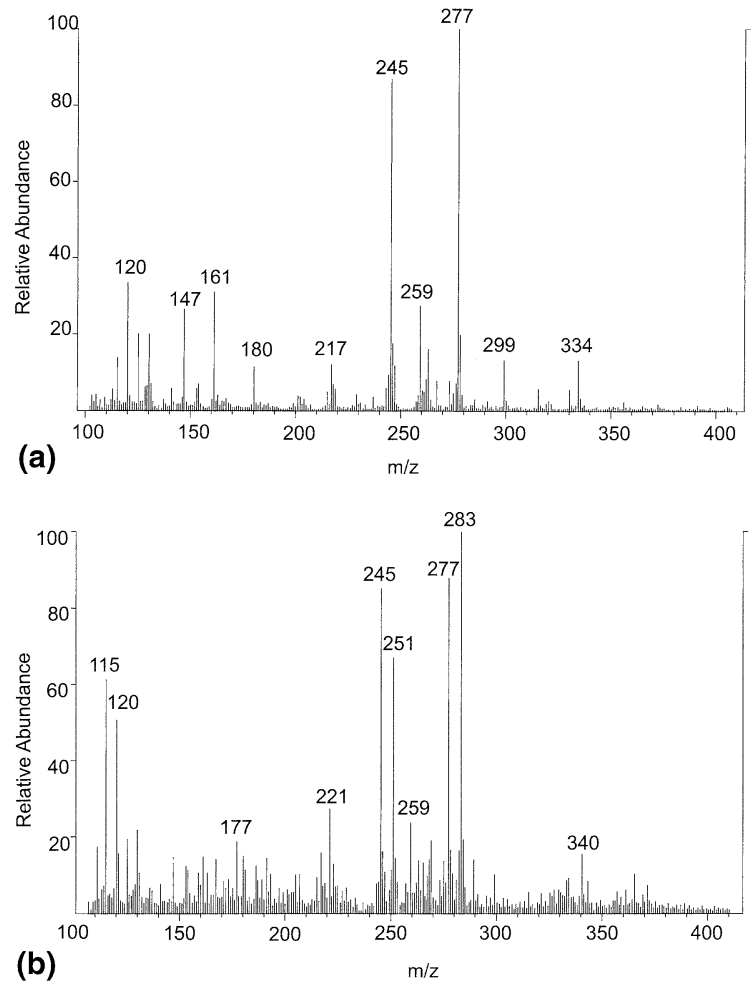

Figure 5. (a) FAB-MS of the hydrazinolysis of Pro-Phe-Gly-Lys $/ t$ $=60 \mathrm{~min}$. (b) FAB-MS of hydrazinolysis of Pro-Phe-Gly-Lys with $\mathrm{LiBr}$ added $/ t=60 \mathrm{~min}$. cleavage from the N-terminus of the modified heptapeptide $(\mathrm{m} / \mathrm{z} 838)$ generating a series of protonated ions at $m / z 767,670,556,443$, and 329. These ions have terminal acid groups, although trace amounts of the corresponding hydrazides are seen in the spectrum at $50 \mathrm{~min}$. Proposed structures were confirmed by accurate mass measurements. Table 1 lists the Akabori reaction products observed in Figure 4 and their measured elemental composition.

The short hand nomenclature used in the descriptor column above, classifies the hydrazinolysis reaction relative to the starting peptide (SP) or in this case the modified peptide. SP is defined as $\mathrm{H}_{-} \mathrm{AA}_{1}-\mathrm{AA}_{2}-\ldots-$ $\mathrm{AA}_{\mathrm{w}-2}-\mathrm{AA}_{\mathrm{w}-1}-\mathrm{AA}_{\mathrm{w}}-\mathrm{OH}$. The first descriptive symbol designates the order of the Akabori reaction, where $\mathrm{Aka}^{1}$ indicates the cleavage of a single C-terminus amino acid while $\mathrm{Aka}^{2}$ would indicate the loss of two amino acids from the C-terminus side. The second symbol defines the extent of amino acid cleavage from the N-terminus side that had occurred prior to the Akabori cleavage (first symbol). Therefore, $\mathrm{AA}_{0}$ depicts an Akabori reaction on $\mathrm{SP}, \mathrm{AA}_{1}$ expresses the Akabori reaction on a peptide produced by the loss of a single amino acid from $\mathrm{N}$-terminus side while $\mathrm{AA}_{1,2,3}$ describes the Akabori reaction on a peptide formed from

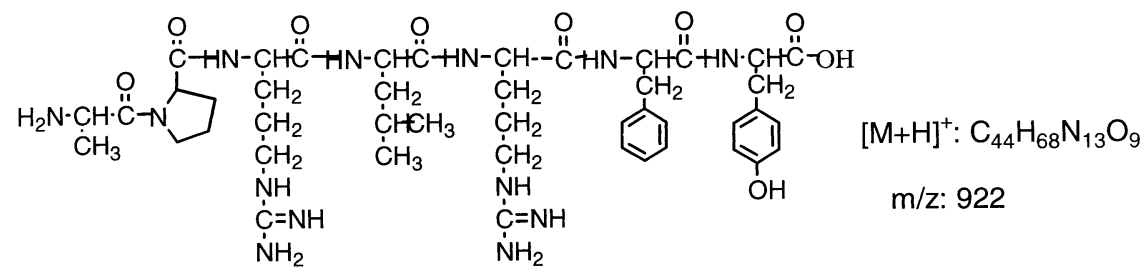
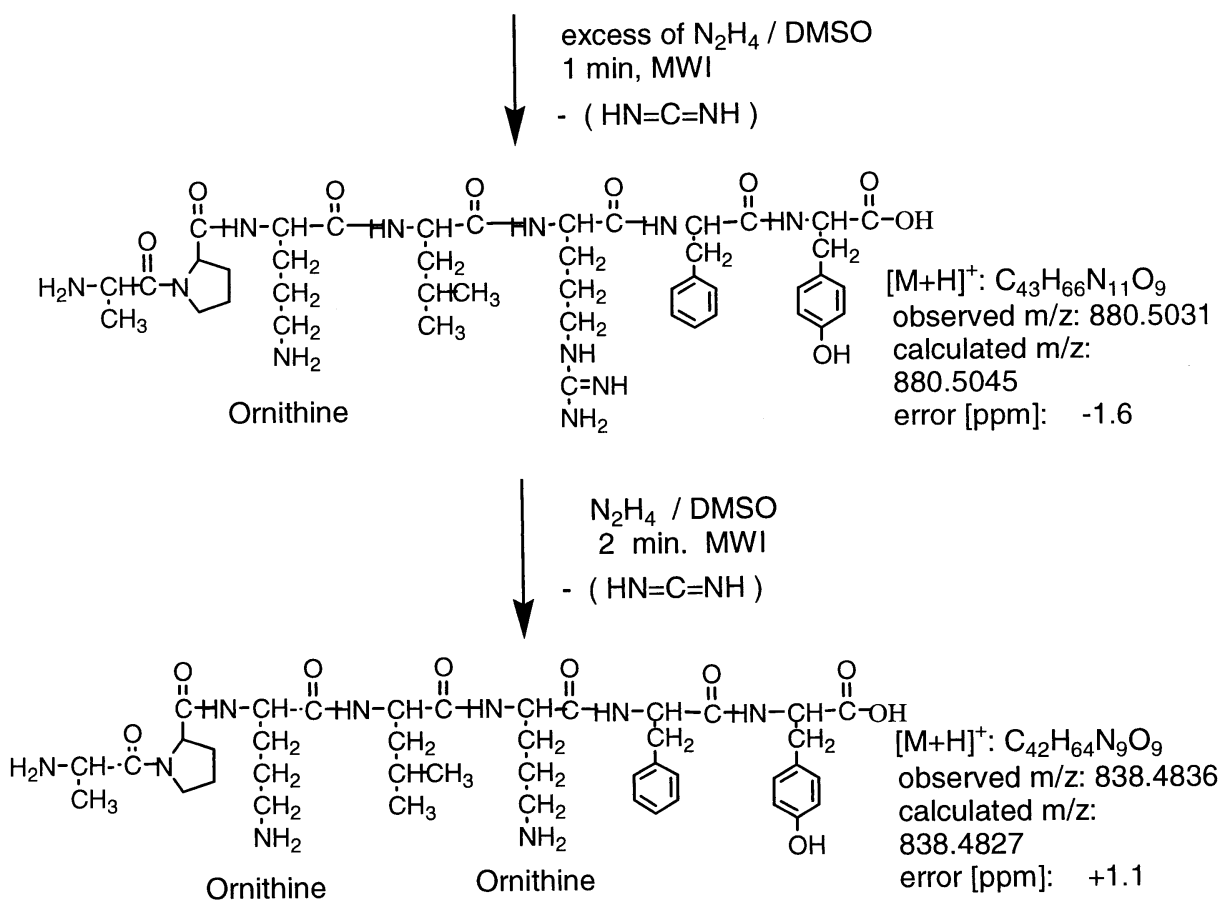

Scheme 8a. Conversion of arginine to ornithine to create modified heptapeptide; occurs during first 2 minutes of hydrazinolysis. 


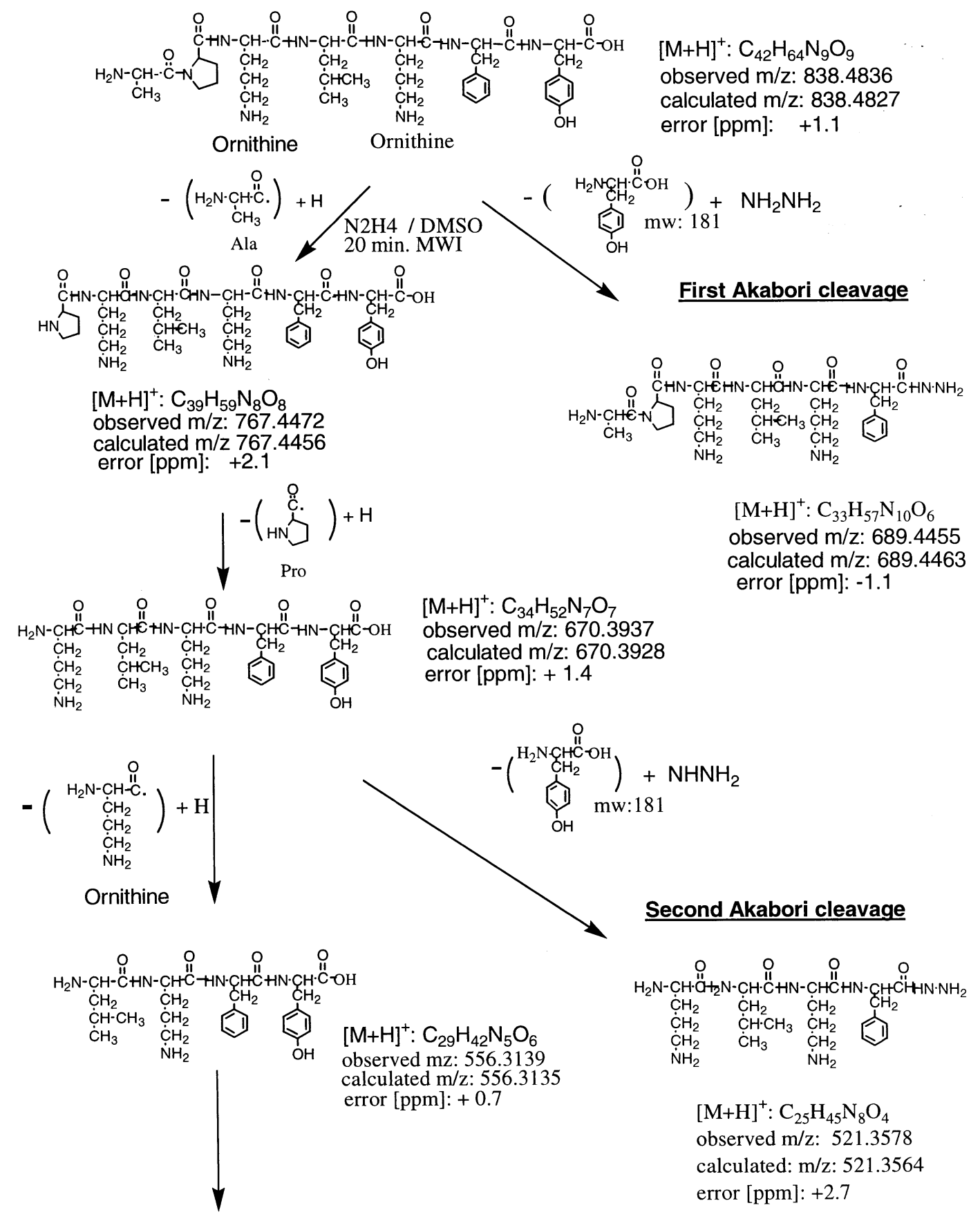

Scheme $8 b$

the loss of three amino acids from the $\mathrm{N}$-terminus side of SP.

The N-terminal amino acid sequence, H-Ala-ProOrn-Leu-Orn-OH, was obtained by subtracting the elemental compositions of consecutive ions in the ion series, $m / z$ 838, 767, 670, 556, 443, and 329. These elemental differences corresponded to the individual amino acids. Since the C-terminus amino acid had also been determined, the identity of the one remaining undefined residue could then be deduced giving the complete peptide sequence. Thus, the complete se- quence was established without repetitive Edman type degradations [3].

The Akabori Reaction of a N-terminus Modified Peptide

Microwave assisted hydrazinolysis of the N-terminal substituted tripeptide, Ac-Met-Leu-Phe-OH, followed the same pattern as the unsubstituted oligopeptides discussed above except that the $\mathrm{N}$-acetyl group was also 


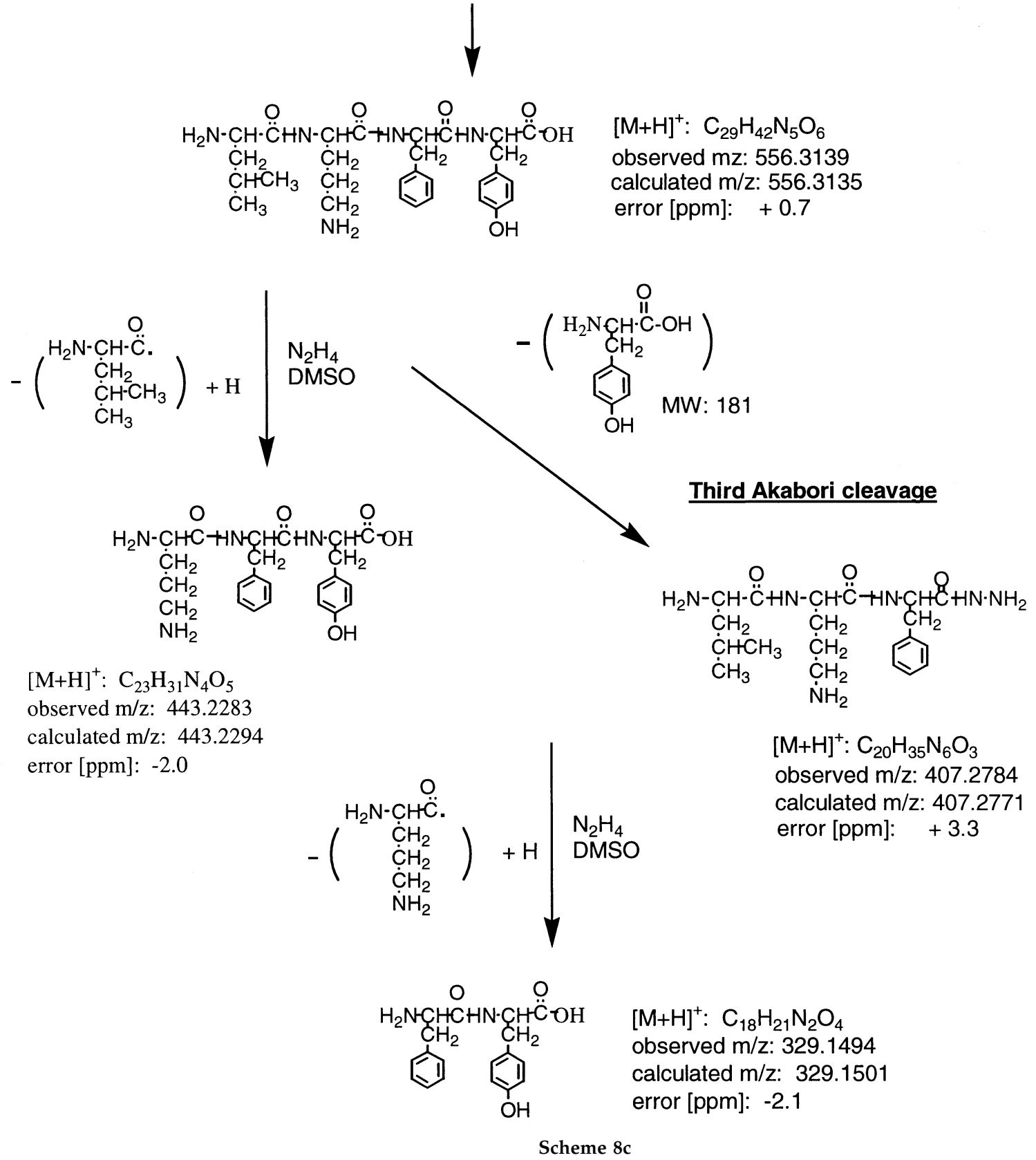

cleaved by hydrazine in some ions to produce regular peptide chains. Thus, the $[\mathrm{M}+\mathrm{H}]^{+}$ion at $\mathrm{m} / z 452$ developed a satellite ion at $m / z 466$ for the corresponding hydrazide Ac-Met-Leu-Phe-NHNH$H_{2}$. The Akabori cleavage led to the expected ion at $m / z$ 319. A parallel set of ions (of reduced intensity) were produced after the loss of the acetyl group through hydrazinolysis at the N-terminus; these ions appeared at $m / z 410,424$. The Akabori approach is therefore applicable even where the conventional Edman degradation would be unsuccessful.

\section{Modification of Amino Acids}

We have noted above that microwave enhanced hydrazinolysis provided rapid indication (or confirma- tion) of the presence of certain amino residues that contain $\mathrm{COOH},-\mathrm{CONH}_{2},-\mathrm{SH}$, and $-\mathrm{NH}-\mathrm{C}(=\mathrm{NH})-\mathrm{NH}_{2}$ groups that interact with hydrazine. The conversion of the carboxy (glutamic acid and aspartic acid) and the carboxamido groups (asparagine and glutamine) to the carboxyhydrazide group, $-\mathrm{CONHNH}_{2}$, leads to the appearance of abundant satellite peaks at $\Delta=+14$ and +15 , respectively. The replacement by $-\mathrm{NHNH}_{2}$ of the $-\mathrm{SH}$ group in cysteine-containing peptides produces a strong satellite peak at $\Delta=-2$. Finally, the rapid loss of $42 \mathrm{Da}(\mathrm{NHC}=$ $\mathrm{NH}$ ) confirms the presence of arginine in a quantitative fashion.

To test the applicability of this method for higher order peptides, the B chain of insulin was subjected to the Akabori reaction using ESI-MS (Figure 6b) as well as 
Table 1. Akabori reaction products and their elemental composition

\begin{tabular}{|c|c|c|c|}
\hline$m / z$ & $\begin{array}{c}\text { Composition } \\
\text { Observed }\end{array}$ & Structure & Descriptor \\
\hline $\begin{array}{l}689 \\
521 \\
407\end{array}$ & $\begin{array}{l}\mathrm{C}_{33} \mathrm{H}_{57} \mathrm{~N}_{10} \mathrm{O}_{6} \\
\mathrm{C}_{25} \mathrm{H}_{45} \mathrm{~N}_{8} \mathrm{O}_{4} \\
\mathrm{C}_{20} \mathrm{H}_{35} \mathrm{~N}_{6} \mathrm{O}_{3}\end{array}$ & $\begin{array}{l}\text { Hydrazide or H-type product ions } \\
\text { H-Ala-Pro-Orn-Leu-Orn-Phe-NHNH } \\
\text { H-Orn-Leu-Orn-Phe-NHNH } \\
\text { H-Leu-Orn-Phe-NHNH } \\
\text { H }\end{array}$ & $\begin{array}{l}\left(\mathrm{Aka}_{1}-\mathrm{AA}_{0}\right) \\
\left(\mathrm{Aka}_{1}-\mathrm{AA}_{1,2}\right) \\
\left(\mathrm{Aka}_{1}-\mathrm{AA}_{1,2,3}\right)\end{array}$ \\
\hline $\begin{array}{l}922 \\
880 \\
\\
838 \\
767 \\
670 \\
556 \\
443 \\
329\end{array}$ & $\begin{array}{l}\mathrm{C}_{43} \mathrm{H}_{66} \mathrm{~N}_{11} \mathrm{O}_{9} \\
\mathrm{C}_{42} \mathrm{H}_{64} \mathrm{~N}_{9} \mathrm{O}_{9} \\
\mathrm{C}_{39} \mathrm{H}_{59} \mathrm{~N}_{8} \mathrm{O}_{8} \\
\mathrm{C}_{34} \mathrm{H}_{52} \mathrm{~N}_{7} \mathrm{O}_{7} \\
\mathrm{C}_{29} \mathrm{H}_{42} \mathrm{~N}_{5} \mathrm{O}_{6} \\
\mathrm{C}_{23} \mathrm{H}_{31} \mathrm{~N}_{4} \mathrm{O}_{5} \\
\mathrm{C}_{18} \mathrm{H}_{21} \mathrm{~N}_{2} \mathrm{O}_{4}\end{array}$ & $\begin{array}{l}\text { Acid or A-type product ions } \\
\text { H-Ala-Pro-Arg-Leu-Arg-Phe-Tyr-OH } \\
\text { H-Ala-Pro-Orn-Leu-Arg-Phe-Tyr-OH } \\
\text { or H-Ala-Pro-Arg-Leu-Orn-Phe-Tyr-OH } \\
\text { H-Ala-Pro-Orn-Leu-Orn-Phe-Tyr-OH } \\
\text { H-Pro-Orn-Leu-Orn-Phe-Tyr-OH } \\
\text { H-Orn-Leu-Orn-Phe-Tyr-OH } \\
\text { H-Leu-Orn-Phe-Tyr-OH } \\
\text { H-Orn-Phe-Tyr-OH } \\
\text { H-Phe-Tyr-OH }\end{array}$ & \\
\hline
\end{tabular}

FAB-MS (Figure 6a) to monitor the reaction. Within 2 min of irradiation, the $[\mathrm{M}+\mathrm{H}]^{+}$ion at $m / z 3497$ correctly lost $42 \mathrm{Da}$ showing the presence of the one arginine residue in this molecule. In addition, the ESI-MS data (Figure 6b) showed the formation of a hydrazide $\left(-\mathrm{CO}-\mathrm{NHNH}_{2}, m / z\right.$ 3512) from amide $\left(-\mathrm{CO}-\mathrm{NH}_{2}\right)$ containing amino acid residue in the molecule. This modified compound ( $\mathrm{m} / \mathrm{z}$ 3512) lost 42 $\mathrm{Da}$ forming an ornithine hydrazide $(\mathrm{m} / \mathrm{z} 3470)$. No
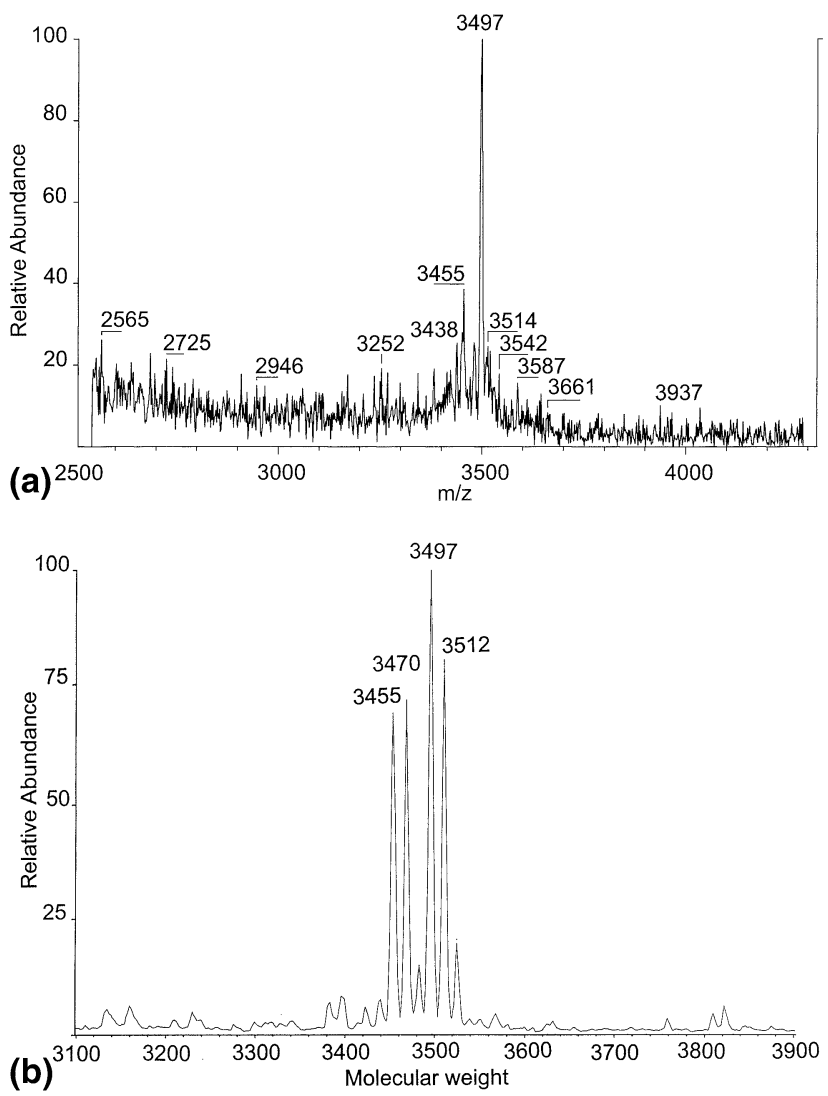

Figure 6. (a) FAB-MS of B chain of Insulin/t $=2 \mathrm{~min}$. (b) ESI-MS of $\mathrm{B}$ chain of Insulin $/ t=2 \mathrm{~min}$. further discernible Akabori type information could be obtained from this experiment. Supplementary studies are required to see if altering the reaction conditions might produce additional structural information from this Akabori reaction. However, one must be cognizant of the possibility that there might be a size limitation to the efficacy of this method.

\section{Conclusion}

We have shown that the microwave assisted Akabori reaction identifies both the C-terminus amino acid as well as furnishes a substantial portion of the amino acid sequence from the $\mathrm{N}$-terminus. In addition, hydrazinolysis provides quantitative information for the presence of amino acid residues containing guanidino, $\beta$-mercapto, carboxy, or carboamido groups. Furthermore, improvements in instrument design, such as monomodal (focused) microwave irradiation (Prolabo Synthewave 402 among others) will provide complete Akabori reactions in 2 or $3 \mathrm{~min}$. Thus, the microwave enhanced hydrazinolysis is a rapid and economical method for solving bioanalytical problems.

\section{Acknowledgments}

The authors are indebted to the National Science Foundation (CHE-9910242), Union Mutual Foundation and the George Barasch Research Fellowship for partial support of this research. The authors also thank Stevens Institute of Technology for allowing use of their laboratory facilities and the Schering-Plough Research Institute for lending them its advanced mass spectrometric instruments.

\section{References}

1. (a) Pramanik, B. N.; Ganguly, A. K.; Gross, M. L. Applied Electrospray Mass Spectrometry. Marcel Dekker, Inc.: New York, 2002, pp 251-281. (b) Kellner, R.; Lottspeich, F.; Meyer, H. E. Microcharacterization of Proteins; 2nd ed. Wiley-VCH: Weinsheim, 1999. 
2. Matsuo, T.; Caprioli, R. M.; Gross, M. L.; Seyama, Y. Biological Mass Spectrometry: Present and Future. Wiley: New York, 1994.

3. Biemann, K. Peptides and Proteins: Overview and Strategy. McCloskey, J. A., Ed. In Methods in Enzymology, Vol CXCIII. Academic Press: San Diego, 1990; pp 351-360.

4. Edman, P. Edman Reaction for Sequencing Peptides. Acta Chem. 1950, 4, 283.

5. Lindh, I.; Hjelmqvist, L.; Bergman, T.; Sjovall, J.; Griffiths, W. J. Sequencing of Peptides Involving C-Terminal Derivatization and Advance Mass Spectrometry. J. Am. Soc. Mass Spectrom. 2000, 11, 673 .

6. Akabori, S.; Ohno, K.; Narita, K. Akabori Reaction for Determining the C-terminus. Bull. Chem. Soc. Japan 1952, 25, 214.

7. (a) Ing, Y. H.; Pramanik, B. N.; Bose, A. K. Microwave Assisted Simplification of the Akabori Method of Peptide Analysis ORGN 0421. Presented at the 218th ACS National Meeting in New Orleans, Louisiana, August 21-27, 1999. (b) Also see, Ing, Y. H. M. S. Thesis, Stevens Institute fo Technology, 2000, pp. 73-130.

8. Gedye, R.; Smith, F.; Westaway, K.; Ali, H.; Baldisera, L.; Laberge, L.; Ronsell, J. The Use of Microwave Ovens for Rapid Organic Synthesis. Tetrahedron Lett. 1986, 27, 279.

9. Giguere, R. J.; Bray, T. L.; Duncan, S. M.; Majetich, G. Application of Commercial Microwave Ovens to Organic Synthesis. Tetrahedron Lett. 1986, 27, 4945.

10. Bose, A. K.; Manhas, M. S.; Ghosh, M.; Raju, V. S.; Tabei, K.; Urbanczyk Lipkowska, Z. Highly Accelerated Reactions in a Microwave Oven: Synthesis of Heterocycles. Heterocycles 1990, 30, 741 .

11. Bose, A. K.; Banik, B. K.; Lavlinskaia, N.; Jayaraman, M.; Manhas, M. S. MORE Chemistry in a Microwave. Chemtech. 1997, 27(9), 18.

12. (a) This communication is Part 16 of Microwave-Induced Organic Reaction Enhancement (MORE) Chemistry. (b) For Part 15, see: Bose, A. K.; Banik, B. K.; Mathur, C.; Wagle, D. R.; Manhas, M. S. Polyhydroxy Amino Acid Derivatives via
$\beta$-Lactams Using Enantiospecific Approaches and Microwave Techniques. Tetrahedron 2000, 56, 5603.

13. (a) Gutierrez, E.; Loupy, A.; Bram, G.; Ruiz-Hitzky, E. Inorganic Solids in "Dry Media." Tetrahedron Lett. 1989, 30, 945. (b) Ben Alloum, A.; Labiad, B.; Villemin, D. Application of Microwave Heating Techniques for Dry Organic Reactions. J. Chem. Soc. Chem. Commun. 1989, 386.

14. (a) Loupy, A.; Petit, A.; Hamelin, J.; Texier-Boullet, F.; Jacquault, P.; Mathe, D. New Solvent-Free Organic Synthesis Using Focused Microwaves. Synthesis 1998, 1213. (b) Varma, R. S. Clay and Clay-Supported Reagents in Organic Synthesis. Tetrahedron 2002, 58, 1235.

15. Cadick, S. Microwave-Assisted Organic Reactions. Tetrahedron 1995, 51, 10403.

16. (a) Hong, B.-C.; Shr, Y.-J.; Liao, J.-H. Unprecedented Microwave Effects on the Cycloaddition of Fulvenes. A New Approach to the Construction of Polycyclic Ring Systems. Org. Lett. 2002, 4, 663. (b) Hong, B.-C.; Jiang, Y.-F.; Kumar, B. S. Microwave-Assisted [6 + 4]-Cycloaddition of Fulvenes and A-Pyrones to Azulene-Indoles: Facile Syntheses of Antineoplastic Agents. Bioorg. Med. Chem. Lett. 2001, 11(15), 1981.

17. Erdelui, M.; Gogoll, A. Rapid Homogeneous-Phase Sonogashira Coupling Reactions Using Controlled Microwave Heating. J. Org. Chem. 2001, 66, 4165.

18. Suib, S. L. Applications of Microwaves in Catalysis. Cattech. 1998, 1, 75.

19. Kabalka, G. W.; Wang, L.; Pagni, R. M. Microwave Enhanced Glaser Coupling Under Solvent-Free Conditions. Synlett. 2001, $1,108$.

20. Chen, S.-T.; Chiou, S.-H.; Wang, K.-T. Enhancement of Chemical Reactions by Microwave Irradiation. J. Chinese Chem. Soc. 1991, 38, 85.

21. Yu, H.-M.; Chen, S. T.; Wang, K.-T. Enhanced Coupling Efficiency in Solid Phase Peptide Synthesis by Microwave Irradiation. J. Org. Chem. 1992, 57, 81. 